\title{
Obstetric and perinatal histories of children who died unexpectedly (cot death)
}

\author{
C. D. PROTESTOS, R. G. CARPENTER,^ P. M. McWEENY, and J. L. EMERY \\ From the Department of Pathology, Children's Hospital, Sheffield
}

\begin{abstract}
Protestos, C. D., Carpenter, R. G., McWeeny, P. M., and Emery, J. L. (1973). Archives of Disease in Childhood, 48, 835. Obstetric and perinatal histories of children who died unexpectedly (cot death). A study has been carried out on the obstetric state and the perinatal and postnatal history of 135 children who died unexpectedly and in whom necropsy was carried out by a paediatric pathologist. All these children were born in one of the units associated with the Medical School at Sheffield. The next child born in the hospital was similarly studied as a control.

A comparison of cases and controls showed 19 features for which the difference between the groups was statistically significant. The most significant new factor found was that of failure of the mother to bring the baby to the first follow-up clinic.

The purpose of the study was to draw up criteria for identifying at birth children who may be at increased risk of unexpected death. Such criteria have been determined from the data presented and are being subjected to clinical trial.
\end{abstract}

There have been many surveys into the environmental factors and the epidemiology of children found unexpectedly dead (Banks, 1958; Bergman, 1970; Carpenter and Shaddick, 1965; Cameron and Asher, 1965; Emery, 1959; Valdés-Dapena, 1967; Houstek, 1969). A recent survey by Froggatt and his colleagues (Froggatt, Lynas, and MacKenzie, 1971) in Northern Ireland largely summarizes previous surveys. These surveys show similar epidemiological results, notably an incidence rate with a sharp age peak at about 3 months which is higher in the winter months, and is higher for male children. Sudden infant deaths also appear more often in lower socioeconomic and underprivileged groups and are associated with such factors as immaturity at birth and the absence of breast feeding.

Considerable uncertainty exists regarding the accuracy of antecedent histories (Emery and Crowley, 1956), and this is the crucial period during which, if preventive methods are to prevail, alerting signs must be recognized. One way of furthering our knowledge (and of preventing these deaths) in this period is to carry out a prospective study on children who are at high risk of succumbing to

\footnotetext{
Received 30 April 1973.

«Present address: Department of Medical Statistics and Epidemiology, London School of Hygiene and Tropical Medicine.
}

unexpected death by selecting children at risk as soon as possible after birth.

Steele and Langworth (1966) used data prospectively collected for the Ontario Perinatal Mortality Study to compare histories of $\mathbf{8 0}$ sudden infant deaths with 157 matched controls. The data covered social and obstetric history; antenatal history, anaesthetic history, and history of the infant after birth. In selecting their cases they had to rely on necropsies carried out by a number of general pathologists and they used controls matched for sex and parity. Thus, some of the differences which typify cases of cot death are lost. The data were not used to construct criteria for detecting high risk children.

As a first step in a long-term project involving a prospective study of children at high risk of unexpected death in Sheffield, it was necessary to attempt to reassess factors occurring during the antenatal and perinatal period in order to produce criteria for the prospective study. For this reason a retrospective assessment has been carried out of the period from the mother's first visit to her doctor to the time when she left the lying-in hospital with the baby.

\section{Material}

In Sheffield the bodies from unexpected deaths in infancy that are referred to the Coroner are transferred to the Children's Hospital where a necropsy is carried 
out by the paediatric pathologist in that hospital. Those cases selected for study were born in one of the 3 main maternity units within the period 1960-72. Controls were also selected from the records of these hospitals. Records of 135 cases were obtained in this way. Therefore, the data on these cases came firstly from the necropsy records of the Department of Pathology of the Children's Hospital where all cases had detailed necropsies and all sections had been examined by one of us (J.L.E.), and secondly from the records of the 3 principal lying-in hospitals within the city, all of which are closely associated with university teaching departments.

For this study the necropsy material and protocol were resurveyed and the cases were divided into four groups.

Group $A$. An unexpected death in a child with a disease of long standing, e.g. heart deformity, hydrocephalus, Down's syndrome.

Group $B$. Necropsy revealed a well-accepted cause of severe disease, e.g. acute adrenal insufficiency, meningitis, acute bronchiolitis.

Group C. A lesion found that would be expected to cause minor but recoverable illness, e.g. tracheitis, small areas of pneumonia.

Group D1. No evidence of definable disease but tissue changes indicating general disturbance such as thymus reaction or rib growth arrest.

Group D2. No abnormality found at all.

Of the 135 babies, all but 7 died at home and were referred through the Coroner as sudden, unexpected deaths. The 7 who died in hospital did so either in the Casualty Department or within minutes of arrival in hospital, or were children on the ward in whom death was as unexpected as if the child had been at home. The latter group would all later be classified under groups $A$ and $B$, and so none of these children would be in the true cot-death group studied in the final analysis in this paper.

The next name in the hospital birth register was used as a control for each case. When this was a twin sib of the case, the name after that was used. Records of all the 135 controls selected were obtained.

\section{Methods}

To abstract the relevant data from the obstetric and paediatric records an extensive coded protocol was devised covering the age of the mother, whether abortion was requested or not, the mother's married status, whether pregnancy was planned or not, the last menstrual period and regularity of cycle, the gestation at which pregnancy was first diagnosed, the mother's blood group including $\mathrm{Rh}$ grouping and presence of antibodies, the reason for hospital confinement, the age at which fetal movements were first recorded, the time at which the mother was first examined either in hospital or by her home doctor, the regularity of attendance at prenatal clinics, and the presence or absence of hydramnios.

The following points were recorded with their time of onset and duration during pregnancy: the presence of mild, moderate, or severe hypertension; vaginal bleeding; proteinuria; oedema of the legs; urinary infection; vaginal discharge; anaemia; psychoneurotic factors; infections including mumps, measles, German measles, chickenpox, flu, and other illnesses; the number and duration of admissions during pregnancy; and the time and reason for the final admission, including postmaturity, failure of growth, toxaemia, etc.

Drugs given during pregnancy were noted in relation to the time during pregnancy that they had been taken, and were grouped as antibiotics, sedatives, anticoagulants, diuretics, hypotensives, iron, and others.

The labour ward data comprised the following: gestational age in weeks on delivery; the presentation at onset of labour; duration of time the membranes were ruptured before delivery and the state of the liquor; whether labour was induced artificially; what drugs were used during labour; the presence or absence of fetal distress; the duration of the different stages of labour; the type of delivery and whether pudendal block, epidural anaesthesia, or episiotomy were carried out; the amount of blood loss during delivery; the form and completeness of the placenta, together with cord length and number of umbilical vessels, cord abnormalities, and occurrence of the cord around the neck.

The sex of the child, birthweight, and length and head circumference were abstracted. Apgar scores were noted at 1 and 5 minutes, and the final classification of the baby as postmature, term, preterm, preterm smallfor-dates or term small-for-dates, was carried out. The occurrence and duration of incubator care and the presence or absence of congenital anomalies at the time of birth were noted.

The duration and day of onset of symptoms occurring in the immediate postnatal period were noted. These comprised cyanotic attacks, pallor, grunting, dyspnoea, twitching, jitteriness, cerebral cry, hypothermia, pyrexia, hypoglycaemia, heart failure, snuffles, and colic. The administration of drugs during the same period was similarly abstracted.

The following were also noted: the date of onset and duration of jaundice and of other factors such as sticky eyes or umbilicus, rashes, mastitis, and oedema, and the presence of bleeding from any site; the time at which meconium was passed; the presence or absence of conjunctival haemorrhage and cephalhaematomas; whether the child was submitted to umbilical catheterization or not, or whether there was any suspicion of heart or nervous system deformity, vomiting, or diarrhoea; the number of days taken to regain birthweight; the age of discharge home and mode of feeding on discharge; whether or not an appointment was given for the baby to attend follow-up clinic, and whether or not he attended.

Further points taken in the family history were the number of miscarriages, stillbirths, and child deaths within the family unit, the occupation of the chief wage earner, the area of Sheffield in which the family resided, and the mother's race. Occupation was used to determine the family's social class as defined by the Office of Population Censuses and Surveys (1970). To examine area of residence the city was subdivided into 9 socioeconomic districts on the basis of studies carried out by R. A. Dixon (personal communication, 1972). 


\section{Obstetric and perinatal histories of children who died unexpectedly (cot death)}

All data abstracted onto the forms had been recorded at the time of the event. No recall data were used. Questions requiring a definite response, e.g. mother's age, were generally complete in over $90 \%$ of the records. Some items were poorly recorded, e.g., the stage of quickening. Symptoms and illnesses in both mother and child could only be abstracted as recorded in the notes. The general quality of the records suggests that such entries will be substantially complete, and analysis has been based on the assumption that no entry corresponds to a negative observation.

The coded data were transferred from the protocols to punched cards for computer analysis. Preliminary analysis was carried out using the RMD 07D program (Dixon, 1971) which provides for visual inspection of the data. This revealed a few punching and coding errors which were corrected.

The bulk of the results presented below are based on variable by variable comparisons of cases in categories $C$ and D only with the controls. A number of multivariate comparisons have also been carried out. These are only briefly alluded to and will be described later elsewhere.

The method of selection of the controls means that cases and controls were only matched for date of birth. Few, if any, of the variables considered are correlated with time of year, except perhaps the occurrence of infections during pregnancy. Further, the distribution of cases in categories $C$ and $D$ by month of birth does not differ greatly from that of cases in categories $\mathrm{A}$ and $\mathrm{B}$. Consequently, when comparing $\mathrm{C}$ and $\mathrm{D}$ cases with controls, all 135 control records have been used.

The data include both qualitative and quantitative variables. Observations on the qualitative variables are presented as percentages, and cases and controls compared by $\chi^{2}$ tests corrected for continuity where appropriate, or, if a cell expectation is very small, an exact test of significance has been computed. The means of continuous variables are shown and the differences compared by ' $t$ ' tests. Some of the continuous variables were, however, recorded on grouped scales which included one or more open-ended groups, e.g. duration of labour is recorded as $<5$ minutes, 5 to 14 minutes, 15 to 30 minutes, etc. Median values are tabulated for these variables and differences were tested by Wilcoxon's signed rank sum test (1945). Continuous variables which had substantially nonnormal distributions have also been compared in this way.

Several problems arise when comparing two groups in many different ways. First, when a large number of significance tests are applied some of the differences are likely to be due to chance and will not reflect real differences between the populations. Second, many of the results may be interrelated and be alternative ways of expressing the same fundamental difference. Another problem is that real differences between the populations may exist, but these may not show up in this particular set of data. In order to minimize this latter effect as far as possible all observed percentage differences greater than $5 \%$ are shown in the ensuing tables. Differences in the continuous variables are likewise shown when $t$, or the standard normal deviate for the Wilcoxon test, is greater than 1. By doing so, if the populations differ by about $10 \%$ in respect to a qualitative variable, the probability that the variable will appear in the tables as one in which differences may exist between the populations is greater than $0 \cdot 8$. Similarly for the continuous variables, if the true difference between the population means exceeds $0.25 \mathrm{SD}$ the variable will probably appear in the tables.

In addition, the results for some variables of special interest are also shown.

\section{Results}

The pathological findings were as follows. Of the 135 cases, $16(11.9 \%)$ belonged to group A, 25 $(18 \cdot 5 \%)$ to group $\mathrm{B}$.

50 children $(37 \cdot 0 \%)$ showed microscopical evidence of minor disease such as mild tracheitis, laryngitis, otitis media, or small areas of pneumonia, i.e. children in whom the amount of lesion found, while perhaps accounting for minor symptoms, would probably not be severe enough to produce lethal disease (group C). Group D comprised 44 $(32.6 \%)$ children who showed no evidence of definable disease in the sense of a definite tracheitis, pneumonia etc., but even among this group the majority (approximately 8 out of 10) showed evidence of previous disturbance of growth or interference with metabolism, e.g. fatty change in the liver. The usual definition (Beckwith, 1970) of 'sudden unexpected death in infancy' corresponds to cases in categories $C$ and D. For the purpose of this investigation these two groups have been combined and compared with controls. Studies of groups $\mathrm{A}$ and $\mathrm{B}$ will be presented elsewhere.

Cases of sudden unexpected death in infancy have been compared with the controls in respect to all the variables describing the pregnancy, delivery, and perinatal state. The results for all variables that may indicate differences of interest between the populations represented by these cases and controls are presented in Tables I, II, and III. These Tables are self explanatory. For all the remaining variables abstracted, only minimal differences were found.

\section{Discussion}

By confining this study to cases referred to the Department of Pathology at the Children's Hospital, some selection of cases may have been introduced; in particular, there may have been selection against the youngest age groups, especially when death occurred in hospital. But the exclusion of such cases of sudden infant death should not affect the present study. Some bias may also have been 
introduced by including only cases born in hospital for whom records were available; but such selection was essential to a retrospective study, and its effects on the results are probably not very great.

The results presented in Tables I, II, and III include some factors which are of interest in that they show no differences between cases and control. The first (shown in Table I) is that abortion was not requested more often for cases than controls. Also, the excess of unmarried mothers among cases is less $(2 \cdot 3 \%)$ than has previously been reported $(10 \%)$ (Carpenter and Shaddick, 1965). The usual association of cases with lower social class appears in the percentage of cases in class V. The distribution of cases by area of residence in Sheffield was similar to that of the controls; this may be due to selection of cases and controls from the same hospital.

Table III shows that the mothers of cases were significantly younger than mothers of the controls, and that they also had significantly more children. These features have appeared in several studies, and Froggatt et al. (1971) have shown that these two factors apply especially to mothers under the age of 30. In the present study discriminant analysis

TABLE I

Results of analysis of qualitative variables

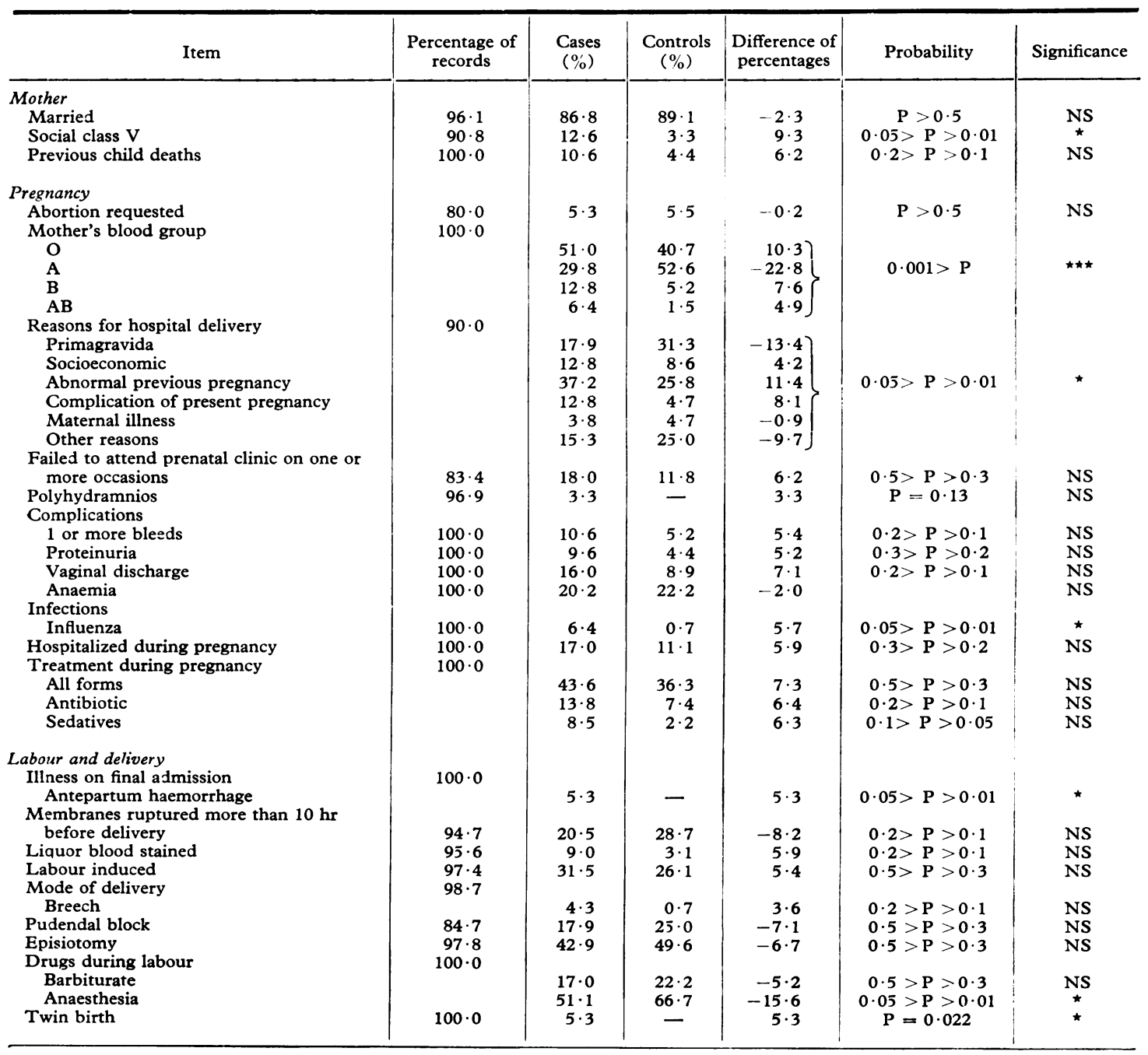




\begin{tabular}{|c|c|c|c|c|c|c|}
\hline Item & $\begin{array}{l}\text { Percentage of } \\
\text { records }\end{array}$ & $\begin{array}{l}\text { Cases } \\
(\%)\end{array}$ & $\begin{array}{l}\text { Controls } \\
(\%)\end{array}$ & $\begin{array}{c}\text { Difference of } \\
\text { percentages }\end{array}$ & Probability & Significance \\
\hline $\begin{array}{l}\text { Baby } \\
\text { Sex-male } \\
\text { Symptoms } \\
\text { Symptoms noted } \\
\text { Dyspnoea } \\
\text { Jitter } \\
\text { Hypoglycaemia } \\
\text { Miscellaneous symptoms } \\
\text { Treatment } \\
\text { Oxygen } \\
\text { Jaundice } \\
\text { Rash } \\
\text { Cephalhaematoma } \\
\text { Discharged home } \\
48 \text { hr or less } \\
\text { 3-7 dy } \\
\text { 8-10 dy } \\
>10 \text { dy } \\
\text { Breast fed on discharge } \\
\text { Clinic appointment kept } \\
\text { Final assessment } \\
\text { Postmature } \\
\text { Term } \\
\text { Preterm } \\
\text { Preterm small-for-dates } \\
\text { Term small-for-dates } \\
\text { Incubator } 24 \text { hr + }\end{array}$ & $\begin{array}{r}100 \cdot 0 \\
100 \cdot 0 \\
100 \cdot 0 \\
100 \cdot 0 \\
95 \cdot 6\end{array}$ & $\begin{array}{r}66 \cdot 0 \\
29 \cdot 8 \\
9 \cdot 6 \\
3 \cdot 2 \\
3 \cdot 2 \\
20 \cdot 2 \\
10 \cdot 6 \\
24 \cdot 5 \\
12 \cdot 8 \\
5 \cdot 3 \\
31 \cdot 1 \\
40 \cdot 0 \\
7 \cdot 8 \\
21 \cdot 1 \\
23 \cdot 8 \\
44 \cdot 4 \\
\\
1 \cdot 1 \\
72 \cdot 2 \\
13 \cdot 3 \\
2 \cdot 2 \\
11 \cdot 1 \\
11 \cdot 2\end{array}$ & $\begin{array}{r}57 \cdot 8 \\
14 \cdot 8 \\
2 \cdot 2 \\
\\
5 \cdot 2 \\
5 \cdot 2 \\
14 \cdot 8 \\
6 \cdot 7 \\
1 \cdot 5 \\
\\
23 \cdot 3 \\
55 \cdot 0 \\
13 \cdot 2 \\
8 \cdot 5 \\
45 \cdot 7 \\
86 \cdot 2 \\
\\
0 \cdot 8 \\
90 \cdot 0 \\
3 \cdot 8 \\
0 \cdot 8 \\
4 \cdot 6 \\
3 \cdot 1\end{array}$ & $\left.\begin{array}{r}8 \cdot 2 \\
15 \cdot 0 \\
7 \cdot 4 \\
3 \cdot 2 \\
3 \cdot 2 \\
15 \cdot 0 \\
5 \cdot 4 \\
9 \cdot 7 \\
6 \cdot 1 \\
3 \cdot 8 \\
7 \cdot 8 \\
-15 \cdot 0 \\
-5 \cdot 4 \\
12 \cdot 6 \\
-21 \cdot 9 \\
-41 \cdot 8 \\
0 \cdot 3 \\
-17 \cdot 8 \\
9 \cdot 5 \\
1 \cdot 4 \\
6 \cdot 5 \\
8 \cdot 1\end{array}\right\}$ & $\begin{array}{c}0.2>P>0.1 \\
0.02>P>0.01 \\
0.05>P>0.02 \\
P=0.13 \\
P=0.13 \\
0.001>P \\
0.3>P>0.2 \\
0.1>P>0.05 \\
0.2>P>0.1 \\
0.3>P>0.2 \\
0.02>P>0.01 \\
0.01>P>0.001 \\
0.01>P>0.001 \\
0.01>P>0.001 \\
0.05>P>0.02\end{array}$ & $\begin{array}{c}\text { NS } \\
\star \\
\star \\
\text { NS } \\
\text { NS } \\
\star \star \star \\
\text { NS } \\
\text { NS } \\
\text { NS } \\
\text { NS }\end{array}$ \\
\hline
\end{tabular}

NS, not significant. $\quad \star P<0.05 ; \star \star P<0.01 ; \star \star \star P<0.001$.

shows that together these two variables are highly significant, more so than when either variable is considered alone. Associated with the larger number of previous pregnancies is the increased occurrence of a previous child death; in only one case had there been two previous child deaths, compared with two among the controls. We have not attempted to determine whether these were cases of cot deaths, but a higher than normal incidence rate of sudden unexpected death among sibs of cases has been reported by several workers (Froggatt et al., 1971; Valdés-Dapena, 1967).

Differences between cases and controls in respect of mother's age and parity show up in other ways in the tables, e.g. primagravida was the reason for hospital confinement in $18 \%$ of the cases and in $31 \%$ of the controls. It will also be noticed that socioeconomic reasons are more common for cases, together with complications of the previous pregnancy.

Table I also shows that cases failed to attend prenatal clinics more often than controls, and were more likely to have had flu during pregnancy. Both these observations are probably manifestations of lower socioeconomical states and larger families. A tendency to postpone or miss prenatal clinics is

TABLE II

Results of analysis of quantitative variables recorded on open-ended scale

\begin{tabular}{|c|c|c|c|c|c|c|}
\hline \multirow{2}{*}{ Item } & \multirow{2}{*}{$\begin{array}{l}\text { Percentage of } \\
\text { records }\end{array}$} & \multicolumn{2}{|c|}{ Median } & \multirow{2}{*}{ Difference } & \multirow{2}{*}{ ND } & \multirow{2}{*}{ Significance } \\
\hline & & Cases & Controls & & & \\
\hline $\begin{array}{l}\text { Pregnancy } \\
\text { Anaemia } \\
\text { Stage at onset (wk) }\end{array}$ & $21 \cdot 4$ & $33 \cdot 2$ & $30 \cdot 6$ & $2 \cdot 6$ & $1 \cdot 22$ & NS \\
\hline $\begin{array}{l}\text { Labour and delivery } \\
\text { Duration 1st stage }(\mathrm{hr}) \\
\text { Duration 2nd stage }(\mathrm{min})\end{array}$ & $\begin{array}{l}83 \cdot 4 \\
84 \cdot 3\end{array}$ & $\begin{array}{r}7 \cdot 7 \\
14 \cdot 1\end{array}$ & $\begin{array}{r}8 \cdot 9 \\
23 \cdot 7\end{array}$ & $\begin{array}{l}-1 \cdot 2 \\
-9 \cdot 6\end{array}$ & $\begin{array}{l}-1 \cdot 26 \\
-3 \cdot 31\end{array}$ & $\underset{\star \star \star}{N S}$ \\
\hline $\begin{array}{l}\text { Baby } \\
\text { Apgar (1 min) } \\
\text { Age when regained birthweight (dy) }\end{array}$ & $\begin{array}{l}94 \cdot 3 \\
75 \cdot 5\end{array}$ & $\begin{array}{l}8 \cdot 80 \\
7 \cdot 0\end{array}$ & $\begin{array}{l}8 \cdot 78 \\
5 \cdot 2\end{array}$ & $\begin{array}{l}0.02 \\
1.8\end{array}$ & $\begin{array}{l}0.06 \\
1.91\end{array}$ & $\begin{array}{l}\text { NS } \\
\text { NS }\end{array}$ \\
\hline
\end{tabular}

NS, not significant. ND, standard normal deviate. $\quad \star \star \star P<0.001$. 
TABLE III

Results of analysis of quantitative variables

\begin{tabular}{|c|c|c|c|c|c|c|}
\hline \multirow{2}{*}{ Item } & \multirow{2}{*}{$\begin{array}{l}\text { Percentage of } \\
\text { records }\end{array}$} & \multicolumn{2}{|c|}{ Mean } & \multirow{2}{*}{ Difference } & \multirow{2}{*}{$t$} & \multirow{2}{*}{ Significance } \\
\hline & & Cases & Controls & & & \\
\hline $\begin{array}{l}\text { Mother } \\
\text { No. of previous pregnancies } \\
\text { Age (yr) }\end{array}$ & $\begin{array}{r}100 \cdot 0 \\
96 \cdot 1\end{array}$ & $\begin{array}{l}1 \cdot 89 \\
24 \cdot 3\end{array}$ & $\begin{array}{l}1 \cdot 28 \\
26 \cdot 0\end{array}$ & $\begin{array}{r}0 \cdot 61 \\
-1 \cdot 7\end{array}$ & $\begin{array}{r}3 \cdot 50 \\
-2 \cdot 45\end{array}$ & 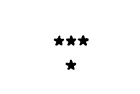 \\
\hline $\begin{array}{l}\text { Pregnaniy } \\
\quad \text { Length of gestation (wk) }\end{array}$ & $98 \cdot 7$ & $39 \cdot 0$ & $39 \cdot 5$ & -0.5 & $-1 \cdot 70$ & NS \\
\hline $\begin{array}{l}\text { Baby } \\
\text { Birthweight (g) } \\
\text { Length (cm) } \\
\text { Head circumference (cm) }\end{array}$ & $\begin{array}{l}98 \cdot 7 \\
47 \cdot 2 \\
51 \cdot 1\end{array}$ & $\begin{array}{r}3098 \\
50 \cdot 6 \\
34 \cdot 1\end{array}$ & $\begin{array}{r}3282 \\
50 \cdot 9 \\
34 \cdot 7\end{array}$ & $\begin{array}{r}-184 \\
--0 \cdot 3 \\
-0 \cdot 6\end{array}$ & $\begin{array}{l}-2 \cdot 32 \\
-0 \cdot 40 \\
-1 \cdot 68\end{array}$ & $\begin{array}{l}\star \\
\text { NS } \\
\text { NS }\end{array}$ \\
\hline
\end{tabular}

NS, not significant. $\quad \star P<0.05 ; \quad \star \star \star P<0.001$.

sufficient to account for the observation that when anaemia was detected it was detected later in mothers of cases than controls (Table II).

Differences in age and parity did not account for the highly significant differences in the length of second-stage labour. A similar but smaller difference in the duration of first-stage labour was also found, but the duration of the third stage was reported to be, on average, identical for cases and controls. This is the first report of such a difference, and it will be interesting to see whether it is repeated elsewhere.

The distribution of blood groups among blood donors reported by Kopec (1970) was $46 \%$ for group $\mathrm{O}, \mathrm{A} 43 \%, \mathrm{~B} 8 \%$, and $\mathrm{AB} 4 \%$. The percentage of $\mathrm{Bs}$ and $\mathrm{ABs}$ among blood donors is higher than in control mothers but lower than for mothers of cases, so that the observed difference may be exaggerated.

The babies that died were significantly lighter than controls and on average were born a few days earlier; measurements of length and head circumference, though made on only about $50 \%$ of the children, showed a similar tendency. An overall clinical assessment of maturity based on gestational age and birthweight showed the usual excess of premature children among the cases. Froggatt et al. (1971) suggested that most of the association of sudden infant death with prematurity can be accounted for by sex, social class, and parity. Multiple birth is another separate factor. Our multivariate analysis shows this may be true; on the other hand, prematurity may still be a useful clinical criteria for detecting high risk children.

Associated with prematurity is an increase in the number of symptoms noted in the baby. The increased incidence of dyspnoea is especially interesting. However, the principal increase is in miscellaneous symptoms such as irritability, poor feeder, oral thrush, mucosy, inspiratory croupy noise, etc. No single factor is specific. Also associated with prematurity and more symptoms is the higher proportion of cases than controls receiving prolonged incubator care. The tendency for cases of sudden unexpected infant death to be associated with the complete absence of breast feeding, first reported by Carpenter and Shaddick (1965), was again observed despite the general decline in breast feeding which has since occurred.

The single most powerful criterion for identifying high risk children was whether, having been given a clinic appointment on discharge from maternity hospital, the appointment was kept. Only $44 \%$ of the cases kept the appointment compared with $86 \%$ of controls. This factor probably represents a cumulation of several of the factors listed above. Unfortunately, the hospitals varied in their practice in issuing recall appointments.

The only comparable study to this one is that of Steele and Langworth (1966). We feel that the records on which our study is based are better than theirs. For example, the ABO blood group was known for the mothers of all our cases and controls compared with only $57 \%$ of theirs. Among the significant factors they listed are four which represent different aspects of the mother's agetheir controls were matched for parity. Besides factors already discussed, they found differences in the mother's smoking habit and in the number of miscarriages and abortions. To ensure that no factor of interest has not been presented we have tabulated many more of our findings. These include a number of new features as already described.

The purpose of this study was to determine criteria for detecting children at increased risk of 
dying unexpectedly. Step-wise discriminant analysis has been used to assemble a set of criteria that can be observed within $\mathbf{4 8}$ hours of birth. A form for collecting and scoring the relevant factors has also been constructed. This is now being subjected to field study and will be published as soon as its value has been assessed.

This work was partly supported by the Foundation for the Study of Infant Deaths.

\section{REFERENCES}

Banks, A. L. (1958). An enquiry into sudden death in infancy. Monthly Bulletin of the Ministry of Health and the Public Health Laboratory Service, 17, 182.

Beckwith, J. B. (1970). Sudden Infant Death Syndrome, p. 17. Ed. by A. B. Bergman, J. B. Beckwith, and C. G. Ray. University of Washington, Seattle and London.

Bergman, A. B. (1970). Sudden infant death syndrome in King County, Washington-epidemiological aspects. In Sudden Infant Death Syndrome, p. 47 . Ed. by A. B. Bergman, J. B. Beckwith, and C. G. Ray. University of Washington, Seattle and London.

Cameron, A. H., and Asher, P. (1965). Cot deaths in Birmingham, 1958-1961. Medical Science and the Law, 5, 187.

Carpenter, R. G., and Shaddick, C. W. (1965). Role of infection, suffocation, and bottle-feeding in cot death. British fournal of Preventive and Social Medicine, 19, 1.
Dixon, W. J. (1971). BMD Biomedical Computer Programs. University of California Press, Berkeley, California.

Emery, J. L. (1959). Epidemiology of 'sudden unexpected, or rapid deaths' in children. British Medical fournal, 2, 925.

Emery, J. L., and Crowley, E. M. (1956). Clinical histories of infants reported to the Coroner as cases of sudden unexpected death. British Medical fournal, $2,1518$.

Froggatt, P. Lynas, M. A., and MacKenzie, G. (1971) Epidemiology of sudden unexpected death in infants (cot death) in Northern Ireland. British fournal of Preventive and Social Medicine, 25, 119.

Houstek, J. (1969). Sudden infant death syndrome in Czechoslovakia: epidemiological aspects. In Sudden Infant Death Syndrome. Proceedings of the 2nd International Conference on Causes of Sudden Death in Infants, p. 55. Ed. by A. B. Bergman, J. B. Beckwith, and C. G. Ray. University of Washington, Seattle.

Kopec, A. C. (1970). The Distribution of the Blood Groups in the United Kingdom. Oxford University Press, London.

Office of Population Censuses and Surveys (1970). Classification of Occupations. H.M.S.O., London.

Steele, R., and Langworth, J. T. (1966). The relationship of antenatal and postnatal factors to sudden unexpected death in infancy. Canadian Medical Association fournal, 94, 1165.

Valdés-Dapena, M. A. (1967). Sudden and unexpected death in infancy. A review of the world literature, 1954-66. Pediatrics, $39,123$.

Wilcoxon, F. (1945). Independent comparisons by randomising methods. Biometrics Bulletin, 1, 80.

Correspondence to Professor J. L. Emery, Department of Pathology, The Children's Hospital, Western Bank, Sheffield S10 3BR. 